\title{
Impact of Gender, Age at Onset, and Lifetime Tic Disorders on the Clinical Presentation and Comorbidity Pattern of Obsessive-Compulsive Disorder in Children and Adolescents
}

\author{
Canan Tanidir, MD, Hilal Adaletli, MD, Hatice Gunes, MD, Ali Guven Kilicoglu, MD, Caner Mutlu, MD, \\ Mustafa Kayhan Bahali, MD, Tugce Aytemiz, MD, and Ozden Sukran Uneri, MD
}

\begin{abstract}
Background: Obsessive-compulsive disorder (OCD) is a heterogeneous disorder; therefore, there is a need for identifying more homogeneous subtypes. This study aimed to examine the clinical characteristics and comorbidity pattern of a large sample of pediatric OCD subjects, and to examine the impact of gender, age at onset, and lifetime tic disorders on the clinical presentation and comorbidity pattern. Methods: A total of 110 children and adolescents diagnosed with OCD were assessed using the Kiddle Schedule for Affective Disorders and Schizophrenia for School Age Children-Present and Lifetime Version (K-SADS-PL) for psychiatric comorbidity, and a clinical data form was filled out. The cutoff for differentiating prepubertal from adolescent onset was 11 years of age.

Results: A total of $83.6 \%$ of the subjects had at least one comorbid psychiatric disorder. Oppositional defiant disorder and contamination/somatic obsessions were significantly higher in males ( $p=0.036$ and $p=0.03$, respectively) than in females. Depressive disorders and religious obsessions were significantly higher in the adolescent-onset group $(p=0.02, p=0.05$, respectively) whereas disruptive behavior disorders were higher in the prepubertal-onset group $(p=0.037)$. Disruptive behavior disorders were significantly more frequent in the tic $(+)$ group than in tic $(-)$ group $(p=0.021)$.

Conclusions: There were differences in the comorbidity pattern and clinical expression between genders and between prepubertal and adolescent-onset cases. Findings of this study supported the introduction of tic-related OCD as a specifier in Diagnostic and Statistical Manual of Mental Disorders, 5th ed. (DSM-5), and the necessity of a detailed assessment of other psychiatric disorders in youth with OCD.
\end{abstract}

\section{Introduction}

C Hildhood OBSESSIVE-COMPUlsive Disorder (OCD) is estimated to affect $1-3 \%$ of the pediatric population (Thomsen 2013) and is associated with significant impairment (Storch et al. 2010; Bipeta et al. 2013). In the Diagnostic and Statistical Manual of Mental Disorders, 4th ed., Text Revision (DSM-IV-TR), OCD was categorized as a subtype of anxiety disorders (American Psychiatric Association 2000) whereas in the Diagnostic and Statistical Manual of Mental Disorders, 5th ed. (DSM-5), it is classified as a different category named "obsessive-compulsive and related disorders," and a subtype of tic-related OCD was introduced (American Psychiatric Association 2013).

High rates of comorbidity are reported in pediatric OCD, with up to $80 \%$ of children affected having at least one comorbid diagnosis and as many as $50-60 \%$ of youth experiencing two or more other mental disorders during their lifetime (Farrell et al. 2012). Main comorbid psychiatric disorders reported in most of the studies in- cluding youth with OCD are anxiety disorders, major depression, tic disorders (TD), and disruptive behavior disorders (DBD) (Masi et al. 2005; Geller 2006; Storch et al. 2008; Langley et al. 2010; Anholt et al. 2014; Bolhuis et al. 2014). Because OCD is a heterogeneous disorder, there has been increased interest in identifying more homogeneous subtypes with distinct patterns of comorbidities (Leckman et al. 2010). Comorbid diagnoses may influence the clinical presentation, treatment, and course of OCD.

Attention has also been directed toward age at onset as an important way of subtyping patients. Many studies suggest that early-onset OCD is a subgroup of the disorder with distinct clinical characteristics, patterns of comorbidity, familiality, and course (Geller et al. 1998; Eichstedt and Arnold 2001; Janowitz et al. 2009). Early-onset OCD is reported to be associated with male preponderance (Albert et al. 2002; Fontenelle et al. 2003; Mancebo et al. 2008; Ruscio et al. 2010; Taylor 2011), a higher familial loading for OCD (Nestadt et al. 2000; Chabane et al. 2005; do Rosario-Campos et al. 2005), and higher comorbidity

Department of Child and Adolescent Psychiatry, Bakırkoy State and Research Hospital for Mental Health and Neurologic Disorders, Istanbul, Turkey.

(C) The Author(s) 2015; Published by Mary Ann Liebert, Inc. This Open Access article is distributed under the terms of the Creative Commons Attribution Noncommercial License (http://creativecommons.org/licenses/by-nc/4.0/) which permits any noncommercial use, distribution, and reproduction in any medium, provided the original author(s) and the source are credited. 
with tics (Chabane et al. 2005; do Rosario-Campos et al. 2005). However there is no consensus about which age should be the cutoff age for differentiating early-onset cases from late-onset ones. The cutoff age differentiating early-onset OCD and late-onset OCD varied from 8 to 25 years in most of studies (Wang et al. 2012).

To date, few studies have compared symptom types and comorbidity patterns across different age groups within a pediatric sample. This study aimed to examine the sociodemographic and clinical characteristics and comorbidity pattern of a large sample of pediatric OCD subjects and to examine the cross-cultural similarities and differences, if any. The other aim of this study was to examine the impact of gender, age at onset, and lifetime tic disorders on the clinical presentation and comorbidity pattern of OCD in children and adolescents.

\section{Methods}

\section{Participants}

Participants were 110 children and adolescents (ages 6-18 years) who were consecutively referred to our outpatient clinic between March 2011 and September 2013 and diagnosed with OCD according to DSM-IV-TR. Subjects who had a psychotic disorder, mental retardation, or pervasive developmental disorder (PDD) were not included in the study.

\section{General clinical data}

A sociodemographic and clinical data form for each patient, prepared by the first author (C.T.), was filled out by the authors themselves by interviewing the parent and the child. This form covers the current age of the child, education level of the parents, presence of any problems during the pre-, peri- or postnatal periods, the main reasons for the referral, age at onset of OCD symptoms, presence of any precipitating stressful events, whether the child perceived obsessions and compulsions as ego-syntonic or egodystonic, family history of OCD, and other psychiatric disorders. In this study, we defined age at onset as the beginning of distressing OCD symptoms as remembered by the patient and/or the parent. A similar definition has been used in previous studies (RosarioCampos et al. 2001, Narayanaswamy et al. 2012). OCD diagnosis was made according to DSM-IV-TR criteria. The presence of any precipitating stressful event was determined by asking both the child and the parents "Do you remember any stressful event just before the beginning of your/your child's symptoms?" or "Do you remember any stressful event that you think caused your/your child's symptoms to occur?" Information about family history was gathered by asking the parents and the child about any psychiatric disorder in both close and distant relatives. Family history of an OCD diagnosis and OCD symptoms were inquired about in detail. All of these clinical data were collected by the authors themselves (eight experts: seven child and adolescent psychiatrists and one clinical psychologist), and it took four sessions to complete the entire clinical assessment.

\section{Assessment of comorbid psychiatric disorders}

Psychiatric comorbidity was assessed using the Kiddie Schedule for Affective Disorders and Schizophrenia for School Age Children-Present and Lifetime Version - Turkish Version (KSADS-PL-T). The KSADS-PL is a semistructured interview schedule designed to assess 32 psychiatric disorders in children and adolescents on the basis of Diagnostic and Statistical Manual of Mental Disorders, 4th ed. (DSM-IV) criteria (American Psychiatric Association 1994; Kaufman et al. 1997). The Turkish version of the
K-SADS-PL was used in this study. The translator demonstrated the reliability and validity of this version (Gökler et al. 2004). All of the interviews were conducted by child and adolescent psychiatrists who were certified and experienced in administering the K-SADSPL and had at least 7 years of experience with anxiety disorders. Lifetime psychiatric diagnoses were examined and noted.

\section{Assessment of obsession-compulsion types}

Obsession-compulsion types were assessed and categorized according to the OCD supplement of K-SADS-PL-T. In this section, obsessions are categorized as: "Contamination/somatic," "aggressive thoughts," "nihilistic or morbid thoughts," "need for symmetry or exactness," "meaningless phrases/sounds/images," "sexual obsessions," "hoarding/saving," "religious," and "other." Compulsions are categorized as: "touching," "counting," "cleaning/washing," "checking," "collecting/hoarding," “ordering/arranging objects," "scheduling activities," "repeating/re-doing," and "other."

\section{Assessment of intellectual abilities}

The Turkish version of the Wechsler Intelligence Scale for Children-Revised (WISC-R) was administered to assess intellectual abilities. All subjects had a full scale intelligence quotient (IQ) $>70$.

\section{Assessment of subgroups}

Children whose age at onset of OCD symptoms was $<11$ years of age (prepubertal onset) were compared with those whose age at onset of OCD symptoms was $\geq 11$ years of age (adolescent onset). This age cutoff was selected as a proxy for puberty, as we did not systematically inquire about pubertal development.

Males and females were compared regarding obsession-compulsion types, age at onset of OCD symptoms, comorbidity pattern, and family history of OCD. Also the subjects who had a lifetime tic disorder (OCD-tic [+]) and the ones who had not (OCD-tic [-]) were compared regarding obsession-compulsion types, age at onset of OCD symptoms, comorbidity pattern, family history of OCD, and perception of OCD symptoms.

\section{Ethics}

The study was approved by the Medical Ethics Committee of the Bakirkoy Research and Training Hospital for Psychiatric and Neurological Disorders. Parents of all children had signed informed consent forms prior to participation in the study. In addition, children $>12$ years of age signed the consent forms themselves.

\section{Statistical analysis}

Data were analyzed using the SPSS (Statistical Package for the Social Sciences), version 16.0 (SPSS, Inc., Chicago, IL).The sample description was done by descriptive analyses: Frequencies and percentages for discrete variables and means and standard errors for continuous variables. Two tailed $\chi^{2}$ test (Fisher's test) was used for comparing categorical variables. A probability level of $p<0.05$ was used to indicate statistical significance.

\section{Results \\ General data}

A total of 110 children and adolescents with OCD (62 girls and 48 boys) were included in the study. The mean age of the sample was 12.17 years (SD: 3.13, range: 6-18) and the mean full-scale IQ score was 95.66 (SD: 13.73 , range: $71-137) ; 79.1 \%$ of the subjects 
were primarily referred for OCD symptoms. Ninety-two subjects $(83.6 \%)$ had at least one comorbid psychiatric disorder. Seventy subjects $(63.5 \%)$ had at least three comorbid psychiatric disorders. The most common comorbid psychiatric disorder groups were anxiety disorders, mood disorders and $\mathrm{DBD}$, respectively. The most common comorbid psychiatric diagnoses were depressive disorders, separation anxiety disorder, specific phobias, and social anxiety disorder respectively (Table 1). The most common obsession types were contamination/somatic, symmetry, and religious obsessions, respectively and the most common compulsion types were cleaning/washing, repeating, and checking compulsions, respectively (Table 2), and $94.6 \%$ of the subjects had both obsessions and compulsions at the same time. Forty-eight subjects $(43.6 \%)$ and/or their parents reported a precipitating psychosocial stressor for the emergence of OCD symptoms. Examples of precipitating psychosocial stressors included hospitalization of a grandmother, witnessing a quarrel between father and uncle, death of a friend, and listening news about pandemic swine flu. Presence of a problem during pre-, peri- or postnatal period was defined in 34 subjects $(30.9 \%)$. Some examples for these problems were: Miscarriage risk, premature birth, need of incubator care just after birth, and gestational hypertension. Ninety subjects $(81.8 \%)$ perceived their OCD symptoms as ego-dystonic, 18 subjects (16.3\%) perceived their symptoms as ego-syntonic, and 2 subjects were indecisive. Mean age of the subjects perceiving their OCD symptoms as egosyntonic was 10.22 (SD: 2.49 , range: 6-16) and $83.3 \%$ were younger than 12 years old; $79 \%$ of the subjects had family history of any psychiatric disorder, $44.5 \%$ had family history of definite OCD, and $22.5 \%$ had family history of subclinical or probable OCD. Mean education years of the mothers and fathers was 6.45 years (SD: 2.73) and 8.71 years (SD: 3.75 ), respectively; $5.3 \%$ of mothers and $13.7 \%$ of fathers had graduated from university.

\section{Gender differences}

Rates of oppositional defiant disorder and contamination/ somatic obsessions were significantly higher in males $(p=0.036$ and $p=0.03$, respectively). There was a trend for a higher rate of sexual obsessions in females than in males, although it was not statistically significant $(p=0.061)$.

\section{Age at onset of OCD symptoms}

The mean age at onset of OCD symptoms was 9.14 years (SD: 3.44, range: 2-16). The distribution of age at onset of OCD is shown in Figure 1. Sixty-nine subjects had prepubertal onset, 41 subjects had adolescent onset. The mean current age of the prepubertal-onset group was 10.5 years (SD: 2.60, range: $6-18$ ) and the mean current age of the adolescent-onset group was 15.05 (SD: 1.54, range: 1118); $78.3 \%$ of the prepubertal-onset subjects were $<12$ years of age. Depressive disorders were significantly higher in the adolescentonset group ( $p=0.02$ ), whereas DBDs were significantly higher in the prepubertal-onset group ( $p=0.037$ ). Religious obsessions were significantly higher in the adolescent-onset subjects $(p=0.05)$. A higher rate of subjects with prepubertal onset perceived their OCD symptoms as ego-syntonic $(p=0.026)$. There was no statistically significant difference between genders regarding age at onset.

\section{Presence of lifetime tic disorder}

A total of $19.1 \%$ of the subjects had a lifetime tic disorder. There were statistically significant differences between the OCD-tic (+) group and OCD-tic (-) group regarding the perception of OCD symptoms and comorbidity pattern. Higher rate of subjects with lifetime tics perceived their OCD symptoms as ego-syntonic $(p=0.04)$. DBDs were significantly more frequent in the OCD-tic $(+)$ group than in the OCD-tic (-) group $(p=0.021)$.

Results are summarized in Tables 1 and 2.

\section{Discussion}

To our knowledge, this is the first study that investigated the clinical characteristics and the comorbid psychiatric disorders by a semistructured clinical interview in a large Turkish sample of children and adolescents with OCD. This study is important for

Table 1. Comparison of the Subgroups According to Obsession and Compulsion Types

\begin{tabular}{|c|c|c|c|c|c|c|c|c|c|c|c|}
\hline & \multicolumn{2}{|c|}{$\begin{array}{c}\text { Total } \\
(\mathrm{n}=110)\end{array}$} & \multirow{2}{*}{$\begin{array}{c}\begin{array}{c}\text { Female } \\
(\mathrm{n}=62)\end{array} \\
\mathrm{n}\end{array}$} & \multirow{2}{*}{$\frac{\begin{array}{c}\text { Male } \\
(\mathrm{n}=48)\end{array}}{\mathrm{n}}$} & \multirow[b]{2}{*}{$\mathrm{p}$} & \multirow{2}{*}{$\begin{array}{c}\begin{array}{c}\text { Prepubertal } \\
\text { onset }(\mathrm{n}=69)\end{array} \\
\mathrm{n}\end{array}$} & \multirow{2}{*}{$\begin{array}{c}\begin{array}{c}\text { Adolescent } \\
\text { onset }(\mathrm{n}=41)\end{array} \\
\mathrm{n}\end{array}$} & \multirow[b]{2}{*}{$\mathrm{p}$} & \multirow{2}{*}{$\begin{array}{c}\begin{array}{c}\text { OCD tic }(-) \\
(\mathrm{n}=89)\end{array} \\
\mathrm{n}\end{array}$} & \multirow{2}{*}{$\frac{\begin{array}{c}\text { OCD tic }(+) \\
(\mathrm{n}=21)\end{array}}{\mathrm{n}}$} & \multirow[b]{2}{*}{$\mathrm{p}$} \\
\hline & $\mathrm{n}$ & $\%$ & & & & & & & & & \\
\hline Obsessions & 106 & 96.4 & 60 & 46 & 1 & 66 & 40 & 0.29 & 85 & 21 & 1 \\
\hline Contamination/somatic & 69 & 62.7 & 31 & 38 & 0.003 & 46 & 23 & 0.42 & 54 & 15 & 0.46 \\
\hline Symmetry & 47 & 42.7 & 27 & 20 & 1 & 29 & 18 & 0.84 & 35 & 12 & 0.15 \\
\hline Religious & 45 & 40.9 & 25 & 20 & 1 & 21 & 24 & 0.003 & 34 & 11 & 0.32 \\
\hline Aggressive thoughts & 28 & 25.5 & 17 & 11 & 0.66 & 15 & 13 & 0.26 & 25 & 3 & 0.27 \\
\hline Sexual obsessions & 24 & 21.8 & 18 & 6 & 0.06 & 13 & 11 & 0.34 & 21 & 3 & 0.56 \\
\hline Collecting/hoarding & 4 & 3.6 & 3 & 1 & 0.63 & 3 & 1 & 1 & 4 & 0 & 1 \\
\hline Other & 21 & 19.1 & 12 & 9 & 1 & 13 & 11 & 0.13 & 15 & 6 & 0.23 \\
\hline Compulsions & 108 & 98.2 & 61 & 47 & 1 & 68 & 40 & 0.53 & 87 & 21 & 1 \\
\hline Cleaning/washing & 75 & 68.2 & 40 & 35 & 0.41 & 52 & 23 & 0.09 & 61 & 14 & 1 \\
\hline Repeating/redoing & 57 & 51.8 & 31 & 26 & 0.70 & 35 & 22 & 0.69 & 44 & 13 & 0.34 \\
\hline Checking & 53 & 48.2 & 34 & 19 & 0.13 & 30 & 23 & 0.17 & 45 & 8 & 0.34 \\
\hline Ordering/arranging objects & 41 & 37.3 & 24 & 17 & 0.84 & 27 & 14 & 0.84 & 32 & 9 & 0.62 \\
\hline Touching & 38 & 34.5 & 19 & 19 & 0.42 & 21 & 17 & 0.21 & 28 & 10 & 0.20 \\
\hline Counting & 29 & 26.4 & 18 & 11 & 0.52 & 18 & 11 & 0.83 & 23 & 6 & 0.79 \\
\hline Collecting/hoarding & 4 & 3.6 & 3 & 1 & 0.63 & 3 & 1 & 1 & 2 & 2 & 0.16 \\
\hline Scheduling activities & 1 & 0.9 & 1 & 0 & 1 & 1 & 0 & 1 & 1 & 0 & 1 \\
\hline
\end{tabular}

Bold indicates imphasis of significance.

OCD, obsessive-compulsive disorder. 
Table 2. Comparison of the Subgroups According to Lifetime Psychiatric Disorders

\begin{tabular}{|c|c|c|c|c|c|c|c|c|c|c|c|}
\hline & \multicolumn{2}{|c|}{$\begin{array}{c}\text { Total } \\
(\mathrm{n}=110)\end{array}$} & \multirow{2}{*}{$\begin{array}{c}\begin{array}{c}\text { Female } \\
(\mathrm{n}=62)\end{array} \\
\mathrm{n}\end{array}$} & \multirow{2}{*}{$\frac{\begin{array}{c}\text { Male } \\
(\mathrm{n}=48)\end{array}}{\mathrm{n}}$} & \multirow[b]{2}{*}{$\mathrm{p}$} & \multirow{2}{*}{$\begin{array}{c}\begin{array}{c}\text { Prepubertal } \\
\text { onset } \\
(\mathrm{n}=69)\end{array} \\
\mathrm{n}\end{array}$} & \multirow{2}{*}{$\frac{\begin{array}{c}\text { Adolescent } \\
\text { onset } \\
(\mathrm{n}=41)\end{array}}{\mathrm{n}}$} & \multirow[b]{2}{*}{$\mathrm{p}$} & \multirow{2}{*}{$\begin{array}{c}\begin{array}{c}\text { OCD tic (-) } \\
(\mathrm{n}=89)\end{array} \\
\mathrm{n}\end{array}$} & \multirow{2}{*}{$\frac{\begin{array}{c}\text { OCD tic }(+) \\
(\mathrm{n}=21)\end{array}}{\mathrm{n}}$} & \multirow[b]{2}{*}{$\mathrm{p}$} \\
\hline & $\mathrm{n}$ & $\%$ & & & & & & & & & \\
\hline Anxiety disorders & 69 & 62.7 & 40 & 29 & 0.23 & 42 & 27 & 0.45 & 52 & 17 & 0.14 \\
\hline Separation anxiety disorder & 31 & 28.2 & 16 & 15 & 0.80 & 17 & 14 & 0.30 & 21 & 10 & 0.08 \\
\hline Specific phobia & 30 & 27.3 & 22 & 8 & 0.09 & 21 & 9 & 0.66 & 22 & 8 & 0.22 \\
\hline Social phobia & 29 & 26.4 & 17 & 12 & 0.79 & 17 & 12 & 0.77 & 22 & 7 & 0.71 \\
\hline Generalized anxiety disorder & 25 & 22.7 & 18 & 7 & 0.11 & 14 & 11 & 0.35 & 21 & 4 & 0.34 \\
\hline Posttraumatic stress disorder & 6 & 5.5 & 3 & 3 & 0.65 & 5 & 1 & 0.25 & 4 & 2 & 0.07 \\
\hline Panic disorder & 5 & 4.5 & 3 & 2 & 1 & 1 & 4 & 0.06 & 3 & 2 & 0.24 \\
\hline \multicolumn{12}{|l|}{ Mood disorders } \\
\hline Depressive disorders & 34 & 30.9 & 22 & 12 & 0.30 & 16 & 18 & 0.02 & 25 & 9 & 0.20 \\
\hline $\begin{array}{l}\text { Adjustment disorder } \\
\text { with depressed mood }\end{array}$ & 1 & 0.9 & 1 & 0 & 1 & 0 & 1 & 0.36 & 1 & 0 & 1 \\
\hline Disruptive behavior disorders & 31 & 28.2 & 15 & 16 & 0.36 & 25 & 6 & $\mathbf{0 . 0 3 7}$ & 20 & 11 & 0.021 \\
\hline ADHD & 24 & 21.8 & 12 & 12 & 0.71 & 19 & 5 & 0.09 & 16 & 8 & 0.13 \\
\hline Oppositional defiant disorder & 13 & 11.8 & 4 & 9 & 0.036 & 10 & 3 & 0.49 & 8 & 5 & $\mathbf{0 . 0 3 7}$ \\
\hline Tic disorders & 21 & 19.1 & 9 & 12 & 0.22 & 13 & 8 & 1 & - & - & - \\
\hline $\begin{array}{l}\text { Elimination disorders } \\
\text { (Enuresis nocturna) }\end{array}$ & 14 & 12.7 & 6 & 8 & 0.39 & 8 & 6 & 0.57 & 11 & 3 & 0.73 \\
\hline
\end{tabular}

Bold indicates imphasis of significance.

OCD, obsessive-compulsive disorder; ADHD, attention-deficit/hyperactivity disorder.

examining the cross-cultural differences/similarities regarding clinical characteristics and comorbidity pattern in youth with OCD and for examining the possible subgroups.

The results are discussed in detail and compared with the results of previous studies in the following section.

\section{Types of obsession-compulsions}

The most common obsessions were contamination/somatic obsessions and the most common compulsions were cleaning/washing compulsions, which is compatible with a similar study including 80 children with OCD (Scahill et al. 2003). The most common three compulsion types found in our study were cleaning/washing, repeating/ redoing and checking compulsions. Mataix-Cols et al. (2008) reported the same three compulsion types as being the most frequent ones in their study with a very large sample of children and adolescents with OCD.

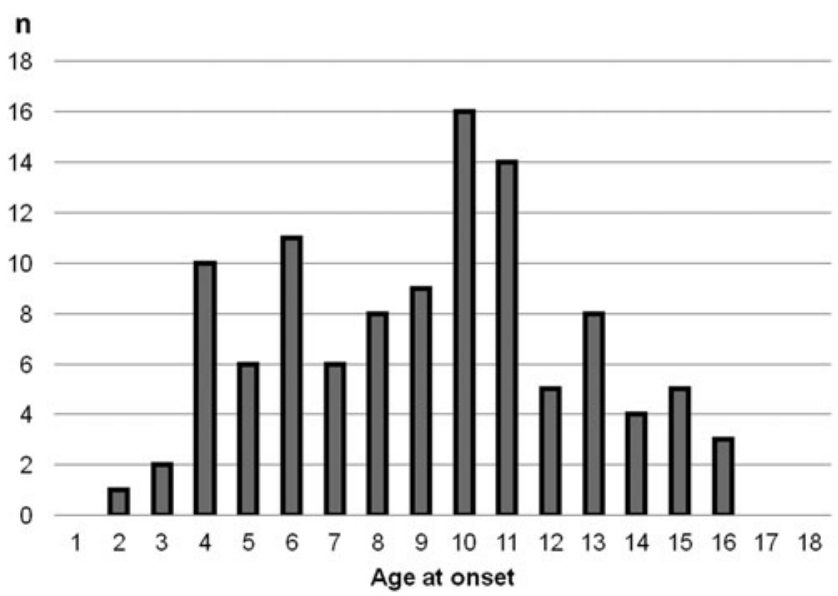

FIG. 1. Distribution of age at onset.

\section{Gender differences}

The preponderance of females in our study is different from most of the studies that found male preponderance in referred children and adolescents with OCD (Thomsen and Mikkelsen 1991; Scahill et al. 2003; Mancebo et al. 2008). However some other studies reported an equal number of affected males and females (Riddle et al. 1990) and studies including adult subjects report equal gender representation, or a slight female preponderance (Geller 2006).

We observed that contamination/somatic obsessions were significantly higher in males, whereas there was a trend for a higher rate of sexual obsessions in females. This is in contrast with a study from Turkey (Tukel et al. 2004) and another study from India (Cherian et al. 2014), which included high number of adult subjects with OCD. Both studies reported that contamination obsessions were significantly more frequently in the female group, whereas sexual obsessions were significantly more common in the male group. The difference between the two studies' and our study's findings may be explained by developmental variability in the phenotypic expression of the disorder, and raises the question of symptom stability by age. However, in their study including 238 children and adolescents with OCD, Mataix-Cols et al. (2008) reported that boys were more likely to have sexual obsessions and another study examining sexual obsessions in children found no gender differences regarding sexual obsessions (Fernandez de la Cruz et al. 2013).

\section{Age at onset of OCD symptoms}

The mean age at onset of OCD symptoms in our sample was 9.14 years, which is consistent with a review of 11 studies reporting a range from 7.5 to 12.5 years (mean, 10.3 years) for age at onset of OCD (Geller et al. 1998). Most of the previous studies (Tukel, et al. 2005; Mancebo et al. 2008; Narayanaswamy et al. 2012) reported that males had an earlier age at onset of OCD, but some studies 
found no difference between males and females (Masi et al. 2005; Janowitz et al. 2009). In our study, there was no significant difference between the two genders regarding age at onset of OCD symptoms.

Religious obsessions were significantly higher in the adolescentonset subjects, which is consistent with some previous studies (Geller, et al. 2001; Scahil et al. 2003). Geller et al. (2001) reported a higher percentage of religious obsessions in adolescents compared with the younger children in their study involving 101 children stratified above and below age 12 years. In this study, the authors proposed that OCD symptoms may follow themes and conflicts appropriate to developmental stages, such as the prominence of sexual and religious preoccupations in adolescence. However in general, our findings are consistent with those reported by Rettew et al. (1992) and Scahill et al. (2003), who found few differences in the frequency of specific obsessions or compulsions across different pediatric age groups.

Another significant difference between the prepubertal-onset and adolescent-onset groups was the perception of their OCD symptoms. A significantly higher rate of prepubertal-onset subjects perceived their OCD symptoms as ego-syntonic. In the definition of obsessions, it is stated that in most individuals obsessions cause marked anxiety or distress. However, this criterion does not apply to all children, and, especially, young children may not always be capable of clearly expressing their sensations and the possible distress caused by the symptoms (Thomsen 2013). Considering that most of the prepubertal-onset subjects in our study were $<12$ years of age, and that all of the adolescent-onset subjects were $\geq 11$ years of age, the difference found between the groups about the perception of the symptoms is not surprising.

DBDs were significantly more frequent in the prepubertal-onset group than in the adolescent-onset group. Similarly, Masi et al. (2005) reported a higher frequency of comorbid DBD in patients with OCD onset before 12 years of age.

Depressive disorders were significantly higher in adolescent onset group. This finding is consistent with the study of Delorme and colleagues, which showed an elevated prevalence of major depressive disorder in late-onset OCD (Delorme et al. 2005).

TD was reported to be higher in early-onset OCD in many studies (Diniz et al. 2004; Narayanaswamy et al. 2012) however we did not find a difference in the rate of comorbid TD between prepubertal- and adolescent-onset cases.

\section{Comorbidity}

In this study, we found a high rate of comorbid psychiatric disorders. Nearly five out of six subjects had at least one comorbid psychiatric disorder and more than half of the subjects had at least three comorbid psychiatric disorders. These rates are similar with the findings of Farrel et al. (2012), reporting a rate of $86 \%$ for a secondary psychiatric disorder, and $74 \%$ for a tertiary psychiatric condition in children and adolescents with OCD. However the high rate of comorbidity found in this study may have stemmed from a selection bias, because we included all of the subjects who had received a diagnosis of OCD according to DSM-IV-TR, although not all of them were primarily referred for OCD symptoms. Nonetheless, nearly four out of five subjects had been referred mainly for OCD symptoms.

The great majority of our subjects had other anxiety disorders, confirming that these disorders are most frequently co-occurring during childhood and adolescence (Masi et al. 2005). In the present study, separation anxiety disorder, specific phobia, social anxiety disorder, and generalized anxiety disorder were the most common anxiety disorders, which is consistent with previous studies (Geller et al. 2001; Masi et al. 2005).

Nearly one third of our patients had a lifetime depressive disorder, which is a consistent finding with the studies reporting the rate of depression in pediatric samples as being between $20 \%$ and 62\% (Bolhuis et al. 2014). Two different views regarding the relationship between OCD and depressive symptoms exist in the literature. One view is that depressive symptoms arise because of the burden and impairment caused by obsessivecompulsive symptoms (Storch et al. 2012). The other view is that the relationship between obsessive-compulsive symptoms and depressive symptoms may be caused by genetic overlap (Bolhuis et al. 2014).

TD and DBD are reported to be highly prevalent in youth with OCD (Geller 2006). In our study, nearly one out of five subjects had comorbid TD and/or attention- deficit/hyperactivity disorder (ADHD), supporting the hypothesis that juvenile OCD is a different subtype of OCD. The comorbidity of TD and OCD has long been recognized in the clinical literature, and appears to be bidirectional. TD and OCD are associated with dysfunction in overlapping neurocortical systems, and family studies have suggested that both conditions represent variable expression of the same underlying risk factors (Lewin et al. 2010). ADHD and OCD are different and separate conditions; however, the high rate of comorbidity between these disorders suggests that they share genetic factors (Walitza et al. 2008). In addition, a genetic family risk analysis examining the relationship between ADHD and OCD in children and adolescents was suggestive of co-segregation between both disorders (Geller et al. 2007).

\section{Impact of lifetime tic disorder}

DBDs were found to be significantly more common in the OCDtic (+) group than in the OCD-tic (-) group. This may be explained by the fact that TD is highly comorbid with DBD. And significantly higher number of OCD-tic (+) subjects perceived their symptoms as ego-syntonic, which is a finding supporting the recent introduction of tic-related OCD as a specifier in DSM-5. OCD-tic (+) seems to be a different subgroup of OCD that has a more developmental nature and in which the obsessive-compulsive symptoms resemble tics phenotypically. Some studies reported that OCD patients with comorbid TD were prevalently male, and more frequently displayed symmetry or aggressive, sexual, or religious obsessions and/or ordering or checking compulsions (Masi et al. 2005). This was not the case in our study. However, considering the modest sample size of the OCD-tic (+) group, it is hard to draw definite conclusions.

\section{Family history and possible etiologic factors}

Research has supported a stronger familial component in childonset cases of OCD in comparison with adult-onset cases (Riddle et al. 1990). The high rate of family history for OCD found in this study confirms the previous studies' results.

Studies have focused also on perinatal experiences of affected subjects (Geller et al. 2008). The high rate of perinatal complications (nearly one third of the subjects) and high rate of precipitating stressors found in this study (nearly half of the subjects) show that environmental factors seem to play an important role, in addition to genetics, in the etiology of OCD. These environmental factors may have facilitated the emergence of OCD in genetically vulnerable individuals. However, the rate of precipitating stressors identified in our study is higher than in Geller's study (2006), which reported a 
rate of $15 \%$ for clear precipitating factors in pediatric OCD subjects. The higher rate of perinatal complications and precipitating factors found in this study may be associated with the profile of our clinic's patients, who come from low-income and less-educated families.

\section{Limitations and strengths}

The strengths of our study are the large sample size and use of a semistructured interview for the assessment of comorbid psychiatric disorders. However, there are some limitations regarding this study that should be taken into account. First of all, a possible selection bias may have inflated the level of comorbidity, as our clinic is one of the biggest general child and adolescent psychiatry clinics in Turkey that also has an inpatient unit. Our clinic serves sometimes as a tertiary clinic, and most of our patients come from low-income and less-educated families, possibly constituting a more severely impaired group, with a greater number of comorbidities, compared with population-based and other clinical samples. Therefore, the generalization of the results to community or other clinical samples of OCD patients should be cautious. Another limitation of our study is the retrospective assessment of some variables (e.g., age at onset, precipitating factors), as there is the possibility of recall bias. In order to increase the reliability of the interview, a parent was also consulted. Lastly, we did not perform any formal reliability exercises for instruments; however, all assessments were made by child and adolescent psychiatrists who were experienced and certified for using K-SADS-PL-T.

Despite these limitations, the current study reinforces the idea that OCD is a heterogeneous disorder with high rates of comorbid psychiatric disorders, and the presence of specific comorbid diagnoses, gender, and the age at onset of the symptoms may influence the clinical presentation of OCD.

\section{Conclusions}

Generally, our results are consistent with the literature, suggesting no major cultural differences in the clinical expression of early-onset OCD (Taylor 2011; Narayanaswamy et al. 2012). There were differences in the comorbidity pattern and clinical expression between the two genders and between the prepubertal and adolescent-onset cases. Differences in the comorbidity pattern and perception of OCD symptoms according to the presence of lifetime tics supported the recent introduction of tic-related OCD as a specifier in DSM-V.

Most of the subjects in our study had more than one additional psychiatric disorder, which shows the necessity of a detailed assessment of the other psychiatric disorders in children and adolescents referred for OCD symptoms. Also, understanding OCD within a developmental perspective is essential for establishing the prognosis and for developing new treatment approaches.

\section{Clinical Significance}

This study is important for examining the impact of gender, age at onset, and lifetime tic disorders on the clinical presentation and comorbidity pattern in a large sample of pediatric OCD subjects from a non-Western country. To date, few studies have compared symptom types and comorbidity patterns across different age groups, and examined the cross-cultural differences within a pediatric sample. Our findings provided additional data to the literature that age at onset and the presence of lifetime tics may be an important way of subtyping OCD patients.

\section{Disclosures}

No competing financial interests exists.

\section{References}

Albert U, Picco C, Maina G, Forner F, Aguglia E, Bogetto F. Phenomenology of patients with early and adult onset obsessive-compulsive disorder [in Italian]. Epidemiol Psichiatr Soc 11:116-126, 2002.

American Psychiatric Association: Anxiety disorders. In: Diagnostic and Statistical Manual of Mental Disorders, 4th ed., Text Revision. Washington, DC: American Psychiatric Association, 2000. Pp. 429-484.

Americn Psychiatric Association: Anxiety, obsessive-compulsive spectrum, posttraumatic, and dissociative disorders. In: Diagnostic and Statistical Manual of Mental Disorders, 5th ed. Arlington, VA: American Psychiatric Association, 235-264, 2013.

American Psychiatric Association. Diagnostic and Statistical Manual of Mental Disorders, 4th ed. Washington, DC: American Psychiatric Association; 1994.

Anholt GE, Aderka IM, van Balkom AJ, Smit JH, Schruers K, van der Wee NJ, Eikelenboom M, De Luca V, van Oppen P: Age of onset in obsessive-compulsive disorder: admixture analysis with a large sample. Psychol Med 44:185-194, 2014.

Bipeta R, Yerramilli SS, Pingali S, Karredla AR, Ali MO: A crosssectional study of insight and family accommodation in pediatric obsessive-compulsive disorder. Child Adolesc Psychiatry Ment Health 7:20, 2013.

Bolhuis K, McAdams TA, Monzani B, Gregory AM, Mataix-Cols D, Stringaris A, Eley TC: Aetiological overlap between obsessivecompulsive and depressive symptoms: a longitudinal twin study in adolescents and adults. Psychol Med 44:1439-1449, 2014.

Chabane N, Delorme R, Millet B, Mouren MC, Leboyer M, Pauls D. Early-onset obsessive-compulsive disorder: a subgroup with a specific clinical and familial pattern? J Child Psychol Psychiatry 46:881-887, 2005.

Cherian AV, Narayanaswamy JC, Viswanath B, Guru N, George CM, Bada Math S, Kandavel T, Janardhan Reddy YC: Gender differences in obsessive-compulsive disorder: findings from a large Indian sample. Asian J Psychiatr 9:17-21, 2014.

Delorme R, Golmard JL, Chabane N, Millet B, Krebs MO, MourenSimeoni MC, Leboyer M: Admixture analysis of age at onset in obsessive-compulsive disorder. Psychol Med 35:237-243, 2005.

Diniz JB, Rosario-Campos MC, Shavitt RG, Curi M, Hounie AG, Brotto SA, Miguel EC: Impact of age at onset and duration of illness on the expression of comorbidities in obsessive-compulsive disorder. J Clin Psychiatry 65:22-27, 2004.

do Rosario-Campos MC, Leckman JF, Curi M, Quatrano S, Katsovitch L, Miguel EC, Pauls DL: A family study of early-onset obsessivecompulsive disorder. Am J Med Genet B Neuropsychiatr Genet 136B:92-97, 2005.

do Rosario-Campos MC, Leckman JF, Mercadante MT, Shavitt RG, Prado HS, Sada P, Zamignani D, Miguel EC: Adults with earlyonset obsessive-compulsive disorder. Am J Psychiatry 158:18991903, 2001.

Eichstedt JA, Arnold SL: Childhood-onset obsessive-compulsive disorder: A tic-related subtype of OCD? Clin Psychol Rev 21:137157, 2001.

Farrell L, Waters A, Milliner E, Ollendick T: Comorbidity and treatment response in pediatric obsessive-compulsive disorder: A pilot study of group cognitive-behavioral treatment. Psychiatry Res 199:115-123, 2012.

Fernandez de la Cruz L, Barrow F, Bolhuis K, Krebs G, Volz C, Nakatani E, Heyman I, Mataix-Cols D: Sexual obsessions in pediatric obsessive-compulsive disorder: clinical characteristics and treatment outcomes. Depress Anxiety 30:732-740, 2013. 
Fontenelle LF, Mendlowicz MV, Marques C, Versiani M: Early- and late-onset obsessive-compulsive disorder in adult patients: an exploratory clinical and therapeutic study. J Psychiatr Res 37:127133, 2003.

Geller DA: Obsessive-compulsive and spectrum disorders in children and adolescents. Psychiatr Clin North Am 29:353-370, 2006.

Geller DA, Biederman J, Faraone S, Agranat A, Cradock K, Hagermoser L, Kim G, Frazier J, Coffey BJ. Developmental aspects of obsessive compulsive disorder: Findings in children, adolescents, and adults. J Nerv Ment Dis 189:471-477, 2001.

Geller D, Biederman J, Jones J, Park K, Schwartz S, Shapiro S, Coffey B: Is juvenile obsessive-compulsive disorder a developmental subtype of the disorder? A review of the pediatric literature. J Am Acad Child Adolesc Psychiatry 37:420-427, 1998.

Geller D, Petty C, Vivas F, Johnson J, Pauls D, Biederman J: Further evidence for co-segregation between pediatric obsessive compulsive disorder and attention deficit hyperactivity disorder: A familial risk analysis. Biol Psychiatry 61:1388-1394, 2007.

Geller DA, Wieland N, Carey K, Vivas F, Petty CR, Johnson J, Reichert E, Pauls D, Biederman J: Perinatal factors affecting expression of obsessive compulsive disorder in children and adolescents. J Child Adolesc Psychopharmacol 18:373-379, 2008.

Gökler B, Unal F, Pehlivanturk B, Cengelkultur E, Akdemir D, Taner Y: Okul Cagı Cocukları Icin Duygulanım Bozuklukları ve Sizofreni Gorusme Cizelgesi - Simdi ve Yasam Boyu Sekli - Turkce Uyarlamasının Gecerlik ve Guvenirligi. Cocuk ve Genclik Ruh Saglıgı Dergisi 11:109-116, 2004.

Janowitz D, Grabe HJ, Ruhrmann S, Ettelt S, Buhtz F, Hochrein A, Schulze-Rauschenbach S, Meyer K, Kraft S, Ferber C, Pukrop R, Freyberger HJ, Klosterkotter J, Falkai P, John U, Maier W, Wagner M: Early onset of obsessive-compulsive disorder and associated comorbidity. Depress Anxiety 26:1012-1017, 2009.

Kaufman J, Birmaher B, Brent D, Rao U, Flynn C, Moreci P, Williamson D, Ryan N: Schedule for Affective Disorders and Schizophrenia for School-Age Children-Present and Lifetime Version (K-SADS-PL): Initial reliability and validity data. J Am Acad Child Adolesc Psychiatry 36:980-988, 1997.

Langley AK, Lewin AB, Bergman RL, Lee JC, Piacentini J: Correlates of comorbid anxiety and externalizing disorders in childhood obsessive compulsive disorder. Eur Child Adolesc Psychiatry 19: 637-645, 2010.

Leckman JF, Denys D, Simpson HB, Mataix-Cols D, Hollander E, Saxena S, Miguel EC, Rauch SL, Goodman WK, Phillips KA, Stein DJ: Obsessive-compulsive disorder: A review of the diagnostic criteria and possible subtypes and dimensional specifiers for DSM-V. Depress Anxiety 27:507-527, 2010.

Lewin AB, Chang S, McCracken J, McQueen M, Piacentini J: Comparison of clinical features among youth with tic disorders, obsessive-compulsive disorder (OCD), and both conditions. Psychiatry Res. 178:317-322, 2010.

Mancebo MC, Garcia AM, Pinto A, Freeman JB, Przeworski A, Stout R, Kane JS, Eisen JL, Rasmussen SA: Juvenile-onset OCD: Clinical features in children, adolescents and adults. Acta Psychiatr Scand 118:149-159, 2008.

Masi G, Millepiedi S, Mucci M, Bertini N, Milantoni L, Arcangeli F: A naturalistic study of referred children and adolescents with obsessive-compulsive disorder. J Am Acad Child Adolesc Psychiatry 44:673-681, 2005.

Mataix-Cols D, Nakatani E, Micali N, Heyman I: Structure of obsessive-compulsive symptoms in pediatric OCD. J Am Acad Child Adolesc Psychiatry 47:773-778, 2008.

Narayanaswamy JC, Viswanath B, Veshnal Cherian A, Bada Math S, Kandavel T, Janardhan Reddy YC: Impact of age of onset of illness on clinical phenotype in OCD. Psychiatry Res 200:554-559, 2012.
Nestadt G, Samuels J, Riddle M, Bienvenu OJ, 3rd, Liang KY, LaBuda M, Walkup J, Grados M, Hoehn-Saric R: A family study of obsessivecompulsive disorder. Arch Gen Psychiatry 57:358-363, 2000.

Rettew DC, Swedo SE, Leonard HL, Lenane MC and Rapoport JL: Obsessions and compulsions across time in 79 children and adolescents with obsessive-compulsive disorder. J Am Acad Child Adolesc Psychiatry 31:1050-1056, 1992.

Riddle MA, Scahill L, King R, Hardin MT, Towbin KE, Ort SI, Leckman JF, Cohen DJ: Obsessive compulsive disorder in children and adolescents: phenomenology and family history. J Am Acad Child Adolesc Psychiatry 29:766-772, 1990.

Ruscio AM, Stein DJ, Chiu WT, Kessler RC: The epidemiology of obsessive-compulsive disorder in the National Comorbidity Survey Replication. Mol Psychiatry 15:53-63, 2010.

Scahill L, Kano Y, King RA, Carlson A, Peller A, LeBrun U, do Rosario-Campos MC, Leckman JF: Influence of age and tic disorders on obsessive-compulsive disorder in a pediatric sample. J Child Adolesc Psychopharmacol 13 Suppl 1:S7-17, 2003.

Storch EA, Larson MJ, Muroff J, Caporino N, Geller D, Reid JM, Morgan J, Jordan P, Murphy TK: Predictors of functional impairment in pediatric obsessive-compulsive disorder. J Anxiety Disord 24:275-283, 2010.

Storch EA, Lewin AB, Larson MJ, Geffken GR, Murphy TK, Geller DA: Depression in youth with obsessive-compulsive disorder: Clinical phenomenology and correlates. Psychiatry Res 196:83-89, 2012.

Storch EA, Stigge-Kaufman D, Marien WE, Sajid M, Jacob ML, Geffken GR, Goodman WK, Murphy TK: Obsessive-compulsive disorder in youth with and without a chronic tic disorder. Depress Anxiety 25:761-767, 2008.

Taylor S: Early versus late onset obsessive-compulsive disorder: Evidence for distinct subtypes. Clin Psychol Rev 31:1083-1100, 2011.

Thomsen PH: Obsessive-compulsive disorders. Eur Child Adolesc Psychiatry 22 Suppl 1:S23-28, 2013.

Thomsen PH, Mikkelsen HU: Children and adolescents with obsessivecompulsive disorder: The demographic and diagnostic characteristics of 61 Danish patients. Acta Psychiatr Scand 83:262-266, 1991.

Tukel R, Ertekin E, Batmaz S, Alyanak F, Sozen A, Aslantas B, Atli H, Ozyildirim I: Influence of age of onset on clinical features in obsessive-compulsive disorder. Depress Anxiety 21:112-117, 2005.

Tukel R, Polat A, Genc A, Bozkurt O, Atli H: Gender-related differences among Turkish patients with obsessive-compulsive disorder. Compr Psychiatry 45:362-366, 2004.

Walitza S, Zellmann H, Irblich B, Lange KW, Tucha O, Hemminger U, Wucherer K, Rost V, Reinecker H, Wewetzer C, Warnke A: Children and adolescents with obsessive-compulsive disorder and comorbid attention-deficit/hyperactivity disorder: Preliminary results of a prospective follow-up study. J Neural Transm 115:187-190, 2008.

Wang X, Cui D, Wang Z, Fan Q, Xu H, Qiu J, Chen J, Zhang H, Jiang $\mathrm{K}$, Xiao Z: Cross-sectional comparison of the clinical characteristics of adults with early-onset and late-onset obsessive compulsive disorder. J Affect Disord 136:498-504, 2012.

Address correspondence to:

Canan Tanidir, $M D$

Child and Adolescent Psychiatry Clinic Bakırköy State Hospital for Mental Health and Neurological Disorders Istanbul 34267 Turkey

E-mail: canantanidir@yahoo.com 